\title{
Optimal Overcurrent Relay Coordination for Sustainable Standalone Hydrokinetic Renewable Energy (SHRE) Distribution Network at Batang Rajang River, Kapit Sarawak by Genetic Algorithm Technique
}

\author{
Saiful Zuhaimi Ahmad ${ }^{1}$, Mohammad Lutfi Othman ${ }^{2}$, Hashim Hizam ${ }^{3}$, Almalik Faisel Mohd. \\ Saupi ${ }^{4}$ and Azimi Che Soh 5 ,* \\ Centre for Advance Power and Energy Research (CAPER), Department of Electrical and Electronic \\ Engineering, Universiti Putra Malaysia, 43400 Serdang, Selangor, Malaysia \\ * Correspondence: szuhaimi@gmail.com; Tel.: +06-013-208-3846 \\ 1-5 These authors contributed equally to this work
}

\begin{abstract}
This paper presents a study on optimization of Overcurrent relay (OCR) coordination protection scheme for Sustainable Standalone Hydrokinetic Renewable Energy (SHRE) distribution network at Batang Rajang river, located at Kapit Sarawak, Malaysia by turning river stream into power generation source. The purpose of the project is to develop rural electrification system for native long houses along the river. The research study is tested on a DigSILENT develop model of the SHRE distribution network and in accordance with all respectively unique parameters and relevant standards. Since this is a new standalone distribution system, an efficient and properly coordinated overcurrent protection system must be provided. Improper and miscoordination among OCRs result in maloperation of the protection system that can lead to false tripping and an unnecessary outage and power system instability. Thus, the objective of this work is to employ Genetic Algorithm (GA) technique in Matlab/Simulink for optimal overcurrent coordination and settings among all OCRs in the proposed distribution network in order to improve the speed of OCR tripping operation. The GA is used because the project is fast track and requiring the simplest method available. In this strategy, time dial setting (TDS) is optimized by using plug setting multiplier (PSM) as the constraint. The obtained results show a significant improvement of the relay operating time of $36.01 \%$ faster than that of conventional numerical technique during fault occurrence. Thus, an efficient and reliable overcurrent protection scheme has been achieved for the SHRE distribution network.
\end{abstract}

Keywords: OverCurrent Relay (OCR); Genetic Algorithm (GA); Time Dial Setting (TDS); Plug Setting Multiplier (PSM); Optimal OCR setting and coordination and DigSILENT power factory

\section{Introduction}

The development of Sustainable Standalone Hydrokinetic Renewable Energy (SHRE) project is to distribute power supply for rural area by harvesting its river current as the alternative energy. The hydrokinetic system uses a very unique horizontal cross flow blade which is developed as shown in Figure 1 to suit the river conditions. The SHRE system is unique, off grid system and successfully installed at the Batang Rajang river, the longest river in Malaysia as Figure 2 to Figure 3. 


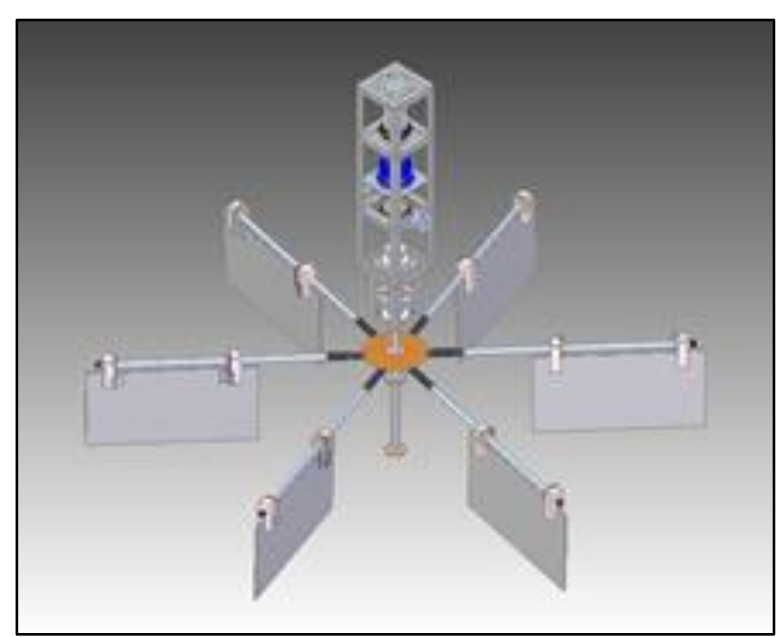

Figure 1. SHRE turbine blade

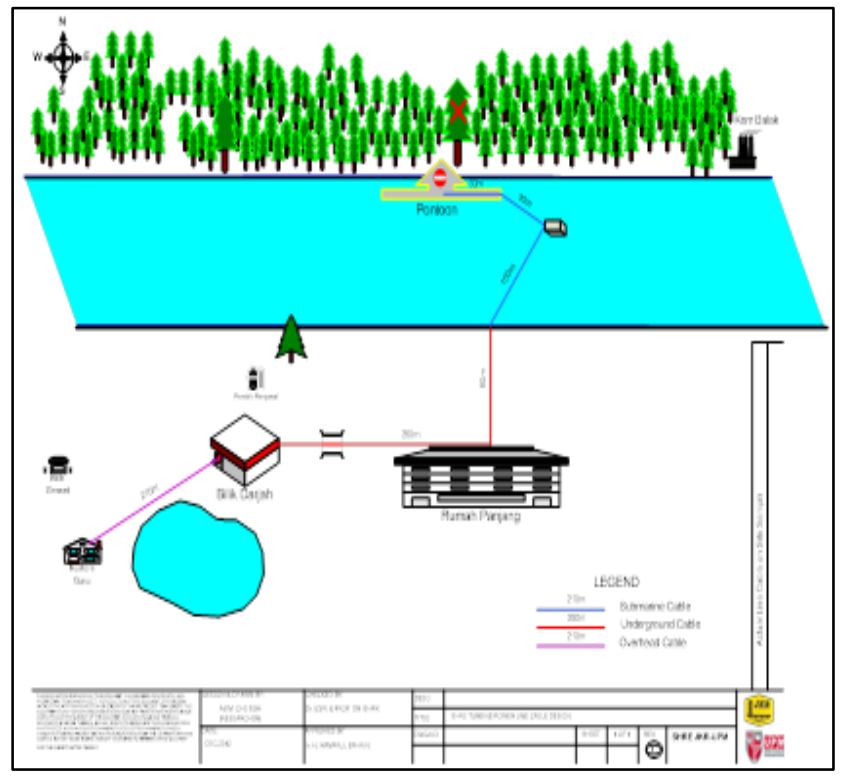

Figure 2. Proposed distribution network

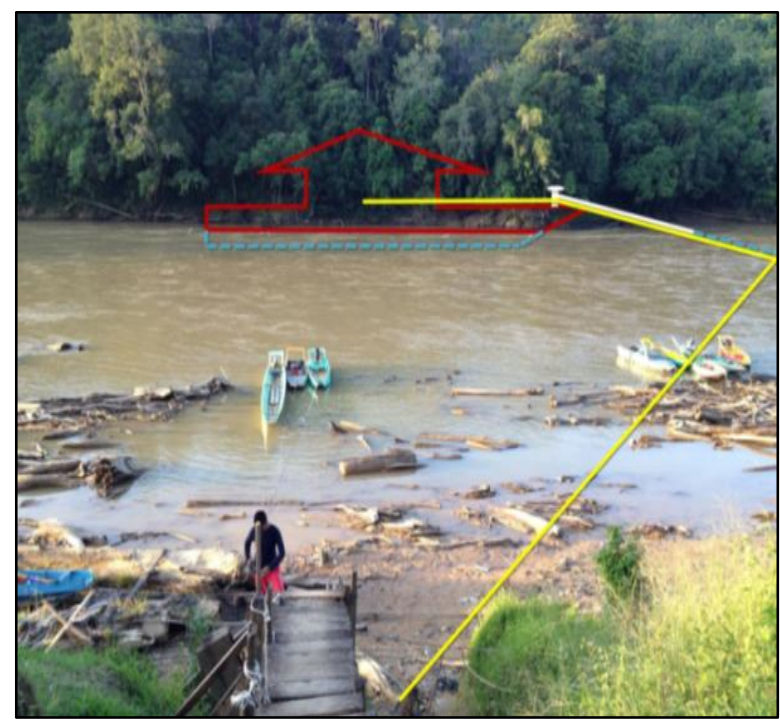

Figure 3. Proposed pontoon location 


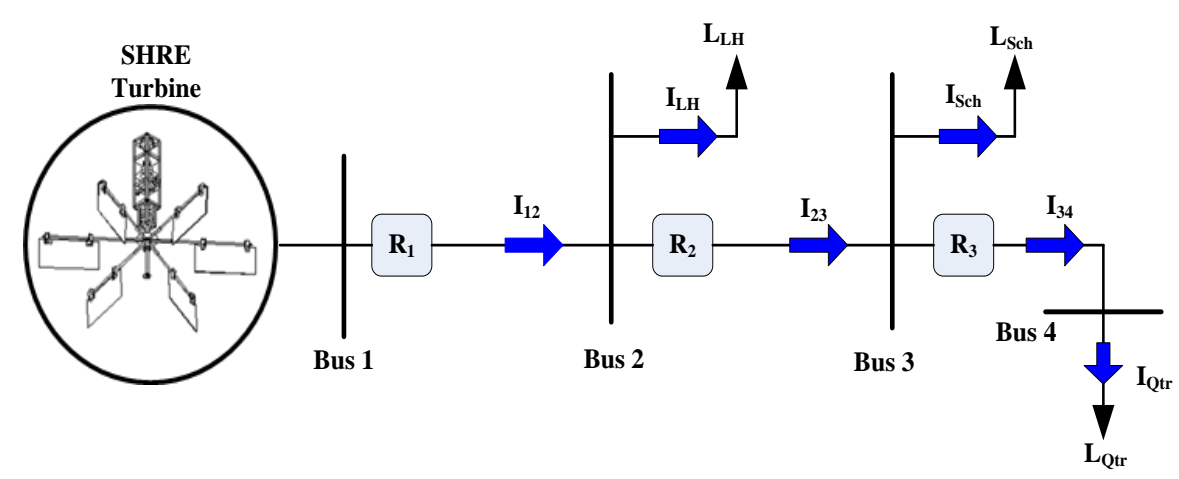

Figure 4. SHRE distribution network equivalent circuit

Several considerations need to be taken into account especially on its reliability and safety of the distribution network to ensure safety, uninterrupted and sustainable production of power [1], [2], [3]. The protection scheme for the mentioned distribution network must be correctly designed and configured in order to avoid and minimize damages to people, equipment and properties during fault occurrence [4]. The protection system should also have functions of improving system stability, detecting faults, separating or isolating faulty section from the rest of the system and restore normal operation after the fault clearance [2]. The study of the reliability of a protection system is critical and must be incorporated with power system reliability studies [4], [5]. There are some standards that need to be complied in providing a protection scheme to any distribution network. The IEEE Standards outlines the characteristic features a protection system must possess dependability and security [6].

\section{Overcurrent relay coordination}

An overcurrent relays (OCRs) are ones of the most common protective devices implemented in power distribution system in limiting the effect of damages by short circuit overcurrent fault [7]. The role of a protective relay is to detect system abnormalities and to selectively execute appropriate commands to isolate only the faulty component from the healthy system. The protective relays monitor the current and voltage of the power system to detect problems in the power system [8]. Protective relays are connected to the power system over instrument transformers known as the current transformer (CT) and the voltage transformer (VT). Figure 6 shows a typical single line diagram in which a protective relay is connected to the power system. The relay itself is also connected to the circuit breaker (CB), which receives trip commands to selectively eliminate the fault. Inverse type overcurrent relay clears the heaviest fault quickly [8], [9]. In the event primary relay fails to operate, a backup protection scheme is provided by backup relay to overcome this circumstance [10]. In order to have a proper coordination between primary and backup relay, the graph theory is used and referred [11]. Further discussion on the overcurrent relay characteristic will be discussed in the next chapter.

\subsection{Overcurrent relay characteristic}

In power system, all of these OCRs must be properly set and coordinated [8], [10]. The operating time of the OCR can vary according to relay type, time dial setting (TDS) and magnitude of the fault current. According to ICE 60255 Standards, the relay operating time can be expressed as in Equation (1) and (2) below. 


$$
\begin{aligned}
& T=\frac{\beta \times T D S}{\left(\left(\frac{I_{\text {SC }}}{I_{\text {Pickup }}}\right)^{\alpha}-\mathbf{1}\right)} \\
& P S M=\left(\frac{I_{S C}}{I_{\text {Pickup }}}\right)
\end{aligned}
$$

Where :-

$\alpha$ and $\beta$ are selected constant

Isc : Short circuit current

Ipickup : Relay pickup current

$P S M$ : Plug setting multiplier

PSM varies in the range of $50 \%$ to $200 \%$ and in steps of $25 \%$ [10]. This setting is only used for inverse current which have different type of characteristic according to IEEE and IEC constant for OCRs that is chosen. PSM is different depending on what type of the selected curve based on the appropriate constant as shown in Table 1.

Table 1. IEEE and IEC constant

\begin{tabular}{ccc}
\hline Curve Type & $\boldsymbol{\alpha}$ & $\boldsymbol{\beta}$ \\
\hline Standard Inverse & 0.02 & 0.14 \\
Very Inverse & 1.0 & 13.5 \\
Extremely Inverse & 2.0 & 80.0 \\
Long-time Inverse & 1.0 & 120 \\
\hline
\end{tabular}

\subsection{Overcurrent relay coordination problem}

The protection arrangement for any power system must take into account the basic principles of reliability, speed and selectivity [12]. These are crucial in relay coordination where the determination of the time delays of all backup relays is performed [13]. There are two groups of relaying equipment for electrical power system protection against short circuit fault on distribution system network [7]. The first is called primary relay and the other backup relay. The primary or main relay is the first line of protection element on any protection system, the failure of which initiates the next line of protection known as the secondary or backup protection relay [13]. An effective coordination scheme ensures that a backup relay always operates at least after a coordination time interval (CTI) in situations where the primary relay fails to initiates or detect same fault earlier [7]. Coordination of these devices for effective protection scheme is very important. In other words, when a short circuit faults occurs, both selected relay pair (primary and backup) normally will start to operate, but primary relay will trip necessary breakers earlier to isolate the short circuited element from the system, while backup relay reset without completing its operational function [14]. Table 2 shows the basic of OCRs coordination and protection scheme in a radial distribution network.

\begin{tabular}{|c|c|c|}
\hline Fault Location & Primary relay & Backup relay \\
\hline Fault No. $3\left(\mathrm{~F}_{3}\right)$ & Relay No. $3\left(\mathrm{R}_{3}\right)$ & Relay No. $2\left(\mathrm{R}_{2}\right)$ \\
\hline Fault No. $2\left(\mathrm{~F}_{2}\right)$ & Relay No. $2\left(\mathrm{R}_{2}\right)$ & Relay No. $1\left(\mathrm{R}_{1}\right)$ \\
\hline Fault No. $1\left(\mathrm{~F}_{1}\right)$ & Relay No. $1\left(\mathrm{R}_{1}\right)$ & - \\
\hline
\end{tabular}

Table 2. Primary relay and backup relay 
Improper and miscoordination among OCRs result in wrong trips of healthy section s and lead to unnecessary outages and compromises the power quality and stability [8]. However, if OCR operating time is too long, it also may result in damages of power apparatus, installation and endanger to personnel safety [15]. For each fault location, taking into account in the event that any of these devices fails, each should be backed up by another protective device. Many methods have been suggested to perform the coordination of OCRs in power distribution system [16]. The suggested methods can be classified into two categories - classical or conventional approaches and modern techniques and approaches [10]. The modern techniques and approaches for OCRs coordination are not only to have optimal solutions for coordinated protection scheme in any electrical distribution network but also to clear faults in the shortest possible time while avoiding false trips due to relay malfunctions. Thus GA optimization technique and approach is selected for this particular study. The relay coordination task described in this paper in the form of constrained optimization problems and an objective function (OF) must be defined accordingly before solving such problem [7].

\subsection{Objective function}

The objective function (OF) is normally expressed in a specified mathematical equation that is used in decision analysis and optimization studies. In this research work, the OF is formulated as below in order to get the optimal solution of it and to avoid overcurrent relay miscoordination [16].

$$
O F=\left(\alpha_{1} \sum_{i=1}^{n}\left(t_{i}\right)^{2}\right)+\left(\alpha_{2} \sum_{m \& b=1}^{n}\left(\Delta t_{1}-\beta\left|\Delta t_{i}\right|\right)\right)^{2}
$$

In this equation, the first term of the Equation (3), $\left(\alpha_{1} \sum_{n=1}^{n}\left(t_{i}\right)^{2}\right)$, is the sum of OCRs operation time. The second term of the above mentioned equation (3), $\left(\alpha_{2} \sum_{m \& b=1}^{n}\left(\Delta t_{i}-\beta\left(\Delta t_{i}-\left|\Delta t_{i}\right|\right)\right)^{2}\right.$ is the coordination constraint. The symbol $\alpha_{1}, \alpha_{2}$ and $\beta$ are the weighting factors which are not only able to increase and empower the concentration of each term but also the GA parameters that can be customized depending on the optimization application. Moreover, $t_{i}$ represents the operating time of OCRs and $\Delta t_{i}$ is the discrimination between the main and backup OCRs.

\section{Methodology}

GA based optimization technique is proposed to reduce the operation time of each relay by improving the coordination between relays. The optimal values for TDS which affect the operation times of each relays according to IEC 60255-151:2009 standard are obtained in this case. The research procedure is depicted as Figure 5. In every application all parameters can be changed to get the best result and optimize the relays. Therefore, every research including this work has its own unique and novel parameters values which would contribute to innovative knowledge. 


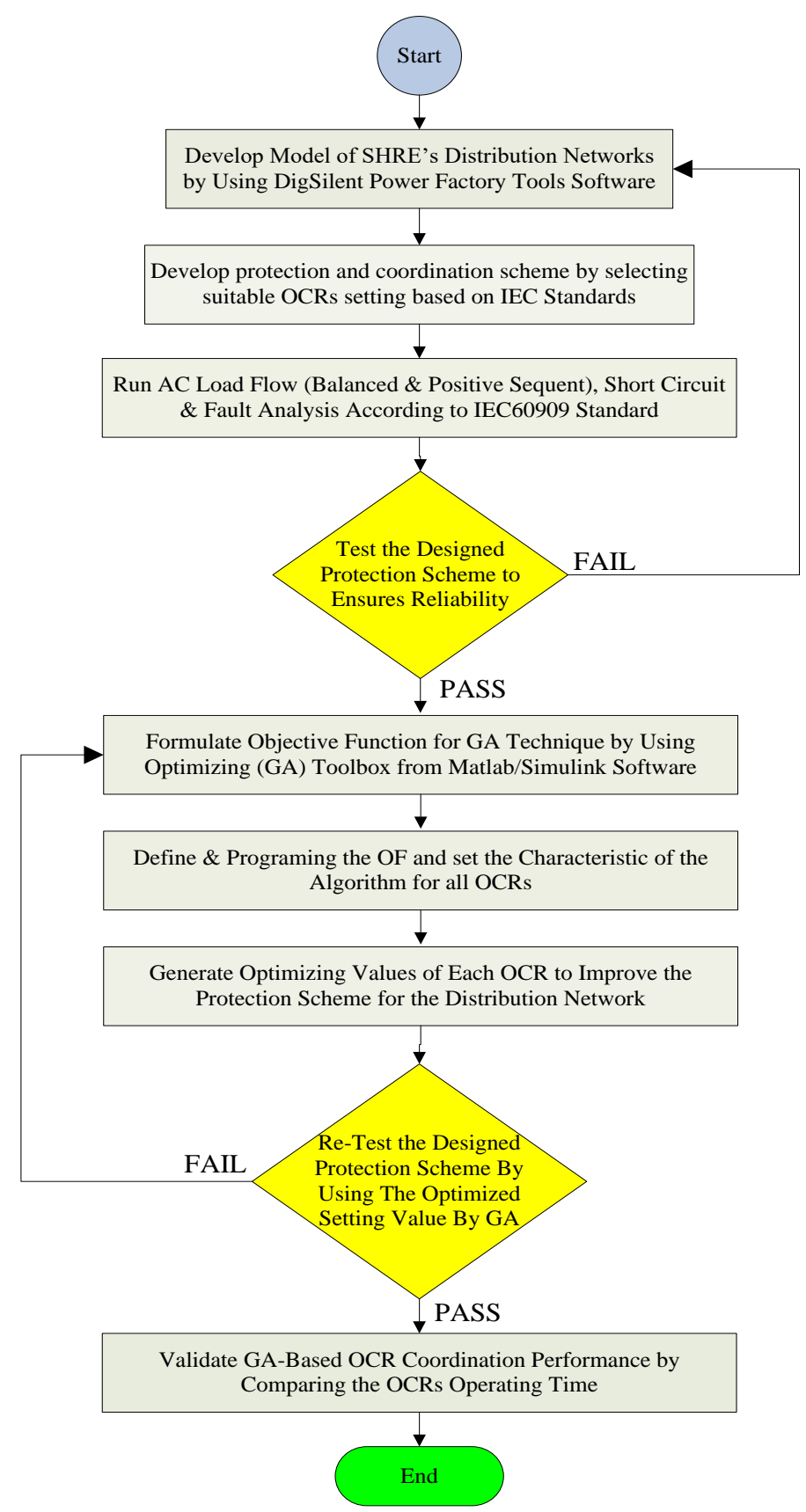

Figure 5. Research flowchart

\subsection{Overcurrent relay characteristic}

Figure 6 shows a model of the SHRE distribution network with actual load data measured at site and it consists of 1 feeder and 4 buses in a radial system. The distribution network is energized by $11 \mathrm{kV}$ generators that connect to $1 \mathrm{MVA} 11 / 0.44 \mathrm{kV}$ step down distribution transformer. The purpose of this configuration is just to make sure the power flow is suitable for fault analysis performed on the distribution side. This entire scheme of power system is for modeling and simulating the intended SHRE distribution network. 


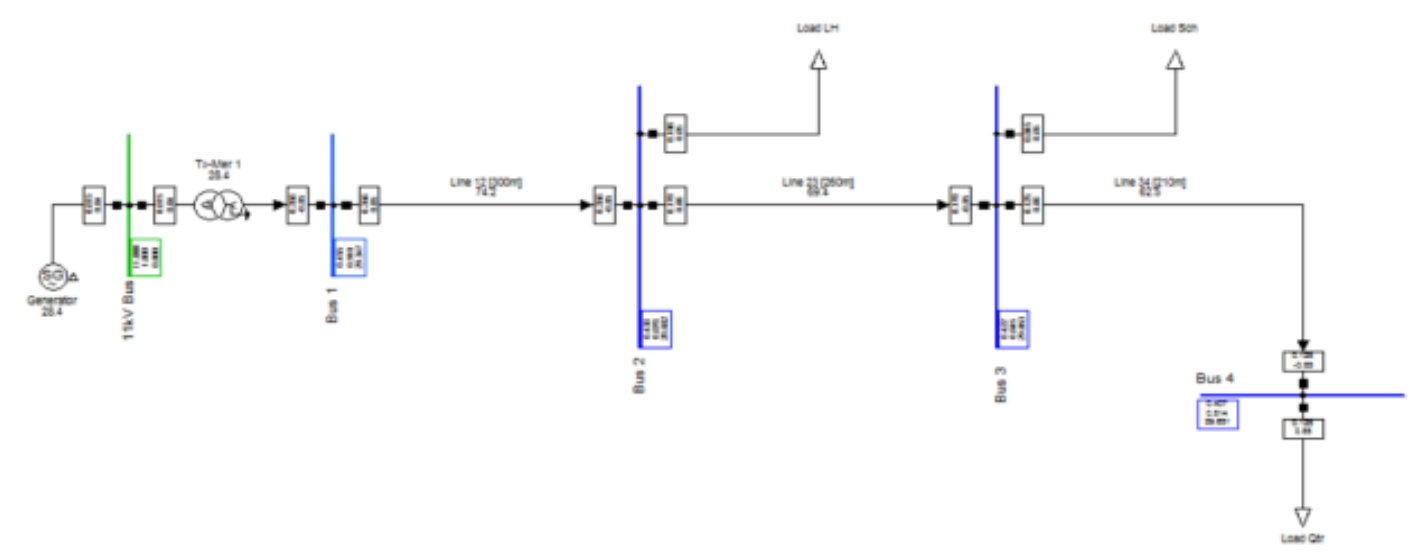

Figure 6. The distribution network

Different capacities of loads are connected into the distribution network, load for Long House (LH) is $120 \mathrm{~kW}$ connected to Bus 2, load for school ( $\mathrm{LSch}$ ) is $28 \mathrm{~kW}$ connected to Bus 3 and load for quarters (LQtr) is $75 \mathrm{~kW}$ connected to bus 4 , as shown in Table 3.

Table 3. SHRE distribution network model's parameters

\begin{tabular}{ccccc}
\hline No. & $\begin{array}{c}\text { Current } \\
{[\mathrm{A}]}\end{array}$ & $\begin{array}{c}\text { Voltage } \\
{[\mathrm{V}]}\end{array}$ & $\begin{array}{c}\text { Load } \\
{[\mathrm{kW}]}\end{array}$ & $\operatorname{Cos} \theta$ \\
\hline 1. & $I_{12}=356.228$ & $V_{B 1}=455$ & 280.737 & 0.85 \\
2. & $I_{L H}=186.092$ & $V_{B 2}=438$ & 120.000 & 0.85 \\
3. & $I_{23}=170.068$ & $V_{B 2}=438$ & 28.000 & 0.85 \\
4. & $I_{\text {sch }}=125.00$ & $V_{B 3}=422$ & 75.000 & 0.85 \\
5. & $I_{Q t r}=125.00$ & $V_{B 4}=407$ & 75.000 & 0.85 \\
\hline
\end{tabular}

From Table 3, simulation on fault current (FC) at any point of distribution network can be carried out in order to provide the protection scheme for the distribution network. In this study, simulation on 3 phase short circuit according to IEC 60909 have been carried out at bus 4 , bus 3 and bus 2. All simulated results are shown in Table 4.

Table 4. Different location of 3 phase short circuit

\begin{tabular}{ccc}
\hline Relay Number & Bus Number & $\begin{array}{c}\text { Fault Current } \\
{[\mathrm{A}]}\end{array}$ \\
\hline $\mathrm{R}_{34}$ & Bus 4 & 3,322 \\
$\mathrm{R}_{23}$ & Bus 3 & 1,853 \\
$\mathrm{R}_{12}$ & Bus 2 & 1,093 \\
\hline
\end{tabular}

\subsection{Implementing GA technique and approach to the distribution model}

In order to minimize the TDS value in GA, an OF and GA coding must be clearly defined by using Matlab. After defining a proper OF and unique parameters, the number of variable must be opted. In this project the variables are the TDSs of OCRs that must be optimized in order to improve the relays operating function and work faster. GA toolbox is used to start simulation and perform the optimization process. 


\section{Results and discussion}

Figure 7 show overcurrent relay characteristic based on IEC 60255 standards. It is also the simulated result of conventional approach form the SHRE distribution network model as described above.

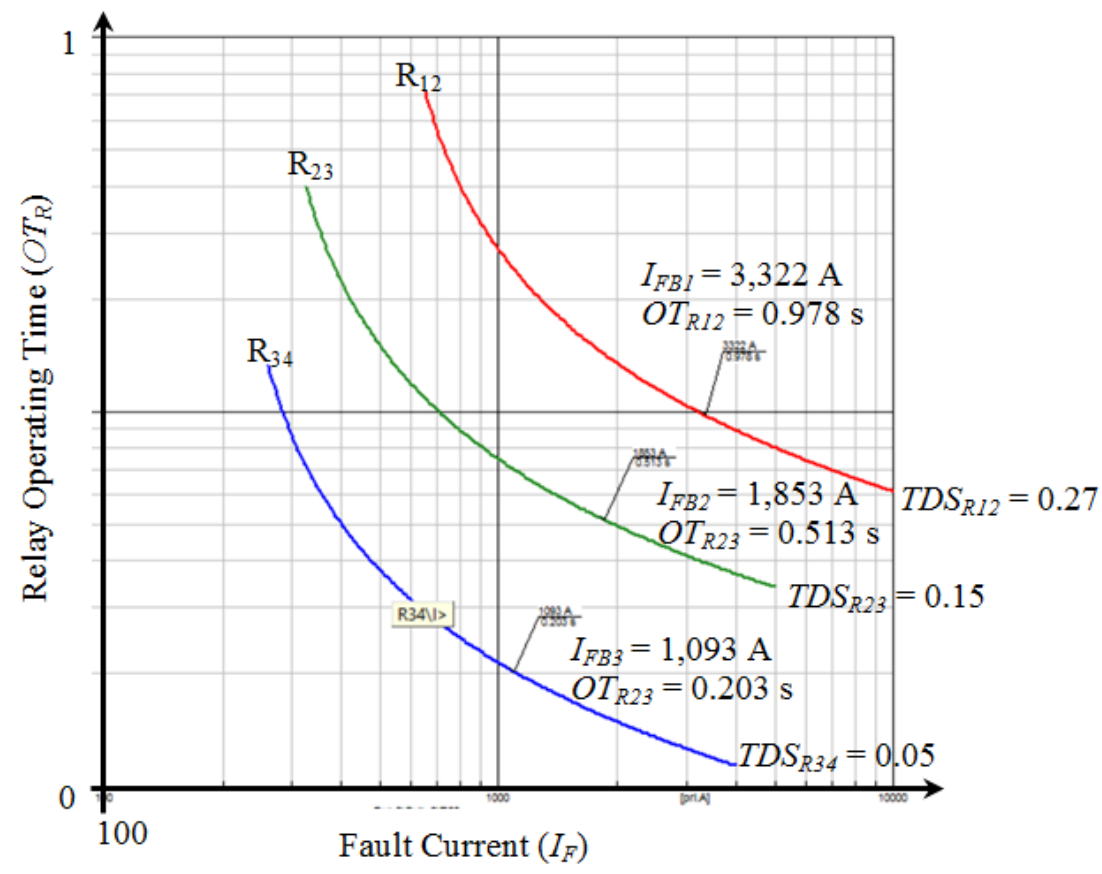

Figure 7. OCR coordination by conventional approach

According to the Figure 7, all OCRs simulation results is now tabulated in Table 5 below. All relay operating times can be verified by applying all data and parameters given in Table 3,4 and 5 into Equation (1) and (2) and also the selection of IDMT curve type - standard inverse. According to Equation (1), the relay operating time is dependent and on TDS value for this particular study. The optimization of TDS values will definitely improve the relay operation time.

Table 5. Relay operating time of OCRs coordination by conventional approach

\begin{tabular}{cccc}
\hline Relay Number & $\begin{array}{c}\text { Fault Current } \\
{[\mathrm{A}]}\end{array}$ & TDS & $\begin{array}{c}\text { Relay Operating Times } \\
\text { [s] }\end{array}$ \\
\hline $\mathrm{R}_{34}$ & 1,093 & 0.05 & 0.203 \\
$\mathrm{R}_{23}$ & 1,853 & 0.15 & 0.513 \\
$\mathrm{R}_{12}$ & 3,322 & 0.27 & 0.978 \\
\hline
\end{tabular}

Figure 8 shows simulated result of OCR coordination by applying GA technique and approach for optimization purpose. The simulation work is tested on the same SHRE distribution network model with exactly the same data and parameters used before. All relays operating time for the same distribution network is tabulated in Table 6. 


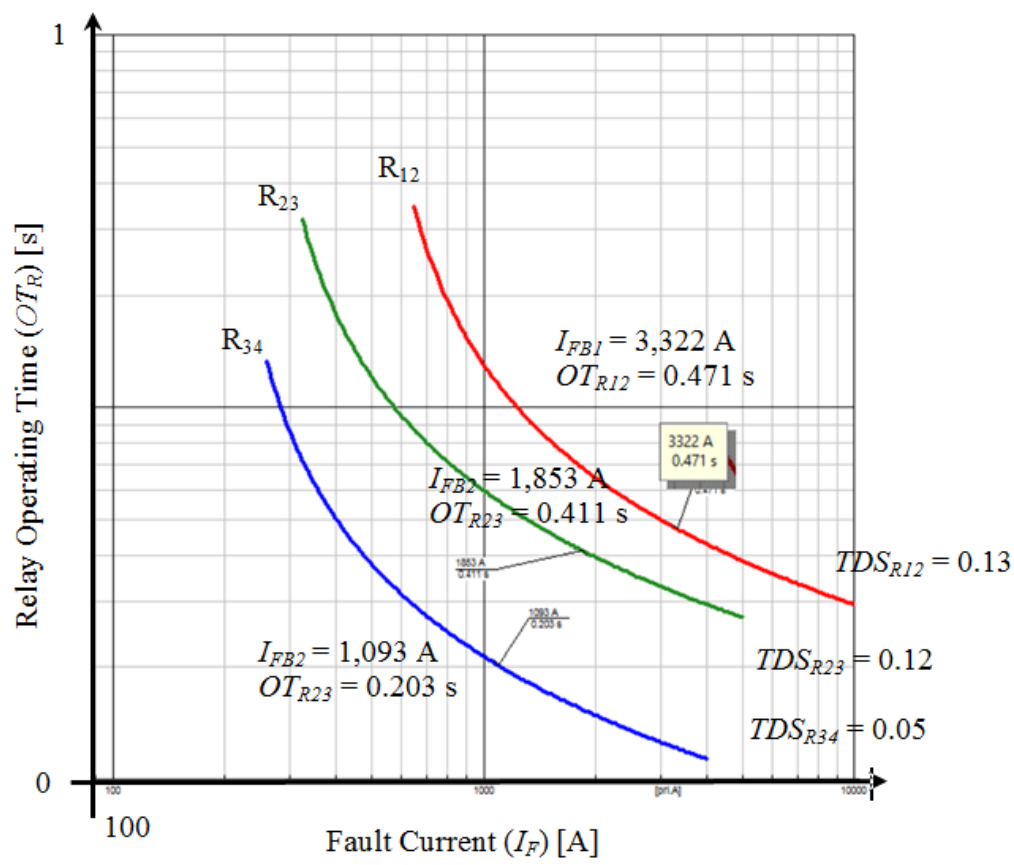

Figure 8. OCR coordination by GA technique

Table 6. Relay operating time of OCRs coordination by GA technique

\begin{tabular}{cccc}
\hline Relay Number & $\begin{array}{c}\text { Fault Current } \\
\text { [A] }\end{array}$ & TDS & $\begin{array}{c}\text { Relay Operating Times } \\
\text { [s] }\end{array}$ \\
\hline $\mathrm{R}_{34}$ & 1,093 & 0.05 & 0.203 \\
$\mathrm{R}_{23}$ & 1,853 & 0.12 & 0.411 \\
$\mathrm{R}_{12}$ & 3,322 & 0.13 & 0.471 \\
\hline
\end{tabular}

The obtained results have clearly shown the improvement of each relay operating time where it is $20 \%$ improvement for $\mathrm{R}_{23}$ and $51.85 \%$ for the $\mathrm{R}_{12}$ and overall improvement is $36.01 \%$ faster than that of conventional numerical technique as shown in Table 7 and thus provided an effective and proper protection scheme and also provide an optimal OCRs coordination setting for the SHRE distribution network.

Table 7. Relay operation time result comparison

\begin{tabular}{cccccc}
\hline Relay & \multicolumn{2}{c}{ Time Dial Setting [TDS] } & \multicolumn{2}{c}{ Relay Operating Time [s] } & Time Reduction \& \\
\cline { 2 - 4 } Number & Conventional & GA Technique & Conventional & GA Technique & Improvement [\%] \\
$\mathrm{R}_{34}$ & 0.05 & 0.05 & 0.2026 & 0.2026 & 0 \\
$\mathrm{R}_{23}$ & 0.15 & 0.12 & 0.5138 & 0.4110 & -20.00 \\
$\mathrm{R}_{12}$ & 0.27 & 0.13 & 0.9793 & 0.4715 & -51.85 \\
Sum & - & - & 1.6957 & 1.0851 & -36.01 \\
\hline
\end{tabular}




\section{Conclusions}

Implementing of GA optimization technique into SHRE distribution network is successfully tested and executed through several sequence procedures. The extracted data from series of simulations such as load flow analysis is successfully verified in order to ensure the unique parameters are used into the distribution network is working properly. The goal of applying GA technique and approach is to get an optimal setting for OCRs coordination for the distribution network has been obtained. Thus, an efficient and reliable overcurrent protection scheme has been achieved for the SHRE distribution network.

Acknowledgement: This research work is a collaboration work between Public Work Department, Government of Malaysia and Universiti Putra Malaysia - SHRE(UPM-JKR), 63000151. Special thanks to Ministry of Energy, Green Technology and Water, Government of Malaysia who give support on financial to carry out this research work.

Author Contributions: Mohammad Lutfi Othman and Hashim Hizam contributed to the literature review of the optimal overcurrent coordination, then developed the discussion about the proposed methodology, discussion about simulation result and analysis and also supervise the research work. Almalik Faisel and Azimi contribute on site installation work, supervised and advised by Kamarul Bahrin Mohamad. All of the authors read and approved the final manuscript.

Conflicts of Interest: The authors declare no conflict of interest during carry out this research work.

\section{References}

[1] J. John, F. Mwasilu, J. Lee, and J. Jung, "AC-microgrids versus DC-microgrids with distributed energy resources: A review," Renew. Sustain. Energy Rev., vol. 24, pp. 387-405, 2013.

[2] A. P. S. Meliopoulos, "Challenges in Simulation and Design of $\mu$ Grids," pp. 309-314, 2002.

[3] M. D. Govardhan, “Grid Technologies - India A Review on Key Issues of Micr rogrid," vol. 24, no. 3, pp. 322-327, 2011.

[4] V. V. Vadlamudi, O. Gjerde, and G. Kjolle, "Dependability and security-based failure considerations in protection system reliability studies," 2013 4th IEEE/PES Innov. Smart Grid Technol. Eur. ISGT Eur. 2013, pp. 9-13, 2013.

[5] C. W. So and K. K. Li, “Overcurrent relay coordination by evolutionary programming,” vol. 53, pp. 8390,2000 .

[6] S. Committee, "IEEE Standard Definitions for Power Switchaear," vol. 1992, 1992.

[7] M. Singh, B. K. Panigrahi, S. Member, and A. R. Abhyankar, “Optimal Overcurrent Relay Coordination in Distribution System," no. 2, 2011.

[8] C. Chen, C. Lee, and C. Chang, "Electrical Power and Energy Systems Optimal overcurrent relay coordination in power distribution system using a new approach," Int. J. Electr. Power Energy Syst., vol. 45, no. 1, pp. 217-222, 2013.

[9] J. Sadeh, I. Member, M. Bashir, S. Member, and E. Kamyab, “Effect of Distributed Generation Capacity on the Coordination of Protection System of Distribution Network," no. 1, pp. 110-115, 2010. 
[10] M. H. Hussain, S. R. A. Rahim, and I. Musirin, “Optimal Overcurrent Relay Coordination : A Review,” Procedia Eng., vol. 53, pp. 332-336, 2013.

[11] T. Amraee, “Coordination of directional overcurrent relays using seeker algorithm," IEEE Trans. Power Deliv., vol. 27, no. 3, pp. 1415-1422, 2012.

[12] D. K. Jain, P. Gupta, and M. Singh, “Overcurrent Protection of Distribution Network with Distributed Generation," Smart Grid Technol. - Asia (ISGT ASIA), 2015 IEEE Innov., 2015.

[13] I. J. I. Systems, M. Zellagui, R. Benabid, M. Boudour, T. H. Boumediene, and A. Chaghi, “Optimal Overcurrent Relays Coordination in the Presence Multi TCSC on Power Systems Using BBO Algorithm," no. January, pp. 13-20, 2015.

[14] M. Ezzeddine and R. Kaczmarek, “A novel method for optimal coordination of directional overcurrent relays considering their available discrete settings and several operation characteristics," Electr. Power Syst. Res., vol. 81, no. 7, pp. 1475-1481, 2011.

[15] S. Hadi, M. Motlagh, and K. Mazlumi, “Optimal Overcurrent Relay Coordination Using Optimized Objective Function," vol. 2014, 2014.

[16] F. Razavi, H. A. Abyaneh, M. Al-Dabbagh, R. Mohammadi, H. Torkaman, and H. Askarian, “A new comprehensive genetic algorithm method for optimal overcurrent relays coordination," Electr. Power Syst. Res., vol. 78, no. 4, pp. 713-720, Apr. 2008. 